\title{
A PARTICIPAÇÃO DOS CONSELHOS DE EDUCAÇÃO NA PROPOSIÇÃO DE POLÍTICAS PÚBLICAS E SEUS LIMITES
}

\author{
Luiz Bezerra Neto ${ }^{1}$ \\ Maria Cristina dos Santos Bezerra ${ }^{2}$ \\ Manoel Nelito M. Nascimento ${ }^{3}$ \\ Universidade Federal de São Carlos - UFSCar
}

\section{RESUMO:}

Este artigo discute a participação dos Conselhos Municipais e Escolares na formulação e avaliação das políticas públicas educacionais em municípios do interior paulista, principalmente com relação a atuação desses órgãos na contratação de parcerias com organizações não governamentais (ONGs), especificamente com o Centro de Estudos e Pesquisas em Educação, Cultura e Ação Comunitária (CENPEC), uma organização da sociedade civil, sem fins lucrativos criada para atuar no campo da educação pública, em 1987, com a finalidade explícita do "desenvolvimento de ações voltadas à melhoria da qualidade da educação pública e à participação no aprimoramento da política social”.

Palavras-chave: política pública - gestão educacional - participação

\section{PARTICIPATION OF THE BOARDS OF EDUCATION IN THE NOMINATION OF PUBLIC POLICY AND ITS LIMITS}

\begin{abstract}
:
This article argues about the participation of the Municipal Councils and Schools in the formulation and evaluation of educational policies in the interior of municipalities, especially regarding the performance of these organs in the partnerships contracting with nongovernmental organizations (NGOs), specificallyin association with the Center for Studies and Research in Education, Culture and Community Action (CENPEC), a civil society nonprofit organization, created to act in the public education grade, in 1987, with the explicit purpose of "development of actions directes to improving the quality of public education and participation in the improvement of social policy. "

Keywords: public politics - education management - participation
\end{abstract}

A constituição brasileira de 1988, rompendo com o espírito autoritário após o fim do regime ditatorial determinou que o país deveria ter uma Lei de Diretrizes e Bases da Educação Nacional diferente da anterior, a lei 4024/61, elaborada no contexto do desenvolvimentismo e que havia sido totalmente modificada pela ditadura civil-militar através das reformulações impostas pela lei 5692/71. Assim, em 1996 foi promulgada a Nova Lei de Diretrizes e Bases da Educação Nacional (LDBEN, 9394/96), como resultado de disputas políticas entre os grupos organizados da sociedade civil que, nas décadas de 1980-90, movidos por anseios de participação no processo de tomada de decisões políticas mobilizou-se reivindicando espaços institucionais de intervenção junto aos órgãos governamentais.

Incorporando muitos princípios defendidos pelo movimento dos educadores dessas décadas e visando melhorar a acessibilidade e a qualidade da educação, o Ministério da 
Educação (MEC) deu início ao processo de reforma educacional, culminando com a referida Lei. Como parte de um projeto político que envolvia inclusive e principalmente, a reformulação do Estado ${ }^{4}$, trouxe em seu bojo a proposta de descentralização administrativa da educação definindo os campos de atuação de cada esfera do poder público federal, estadual e dos municípios.

A discussão sobre a democratização da educação pública tornou-se pauta obrigatória tanto no meio acadêmico quanto nas instituições escolares ao mesmo tempo em que, do ponto de vista político-social, entrou em curso a desresponsabilização do Estado pelos programas sociais em que este transferia para organismos privados da sociedade civil parte da responsabilidade por serviços públicos.

Este texto discute a participação dos Conselhos Municipais e escolares na formulação e avaliação das políticas públicas educacionais em municípios do interior paulista, principalmente com relação a atuação desses órgãos na contratação de parcerias com organizações não governamentais (ONGs), especificamente com o Centro de Estudos e Pesquisas em Educação, Cultura e Ação Comunitária (CENPEC), uma organização da sociedade civil, sem fins lucrativos, para o desenvolvimento do projeto "Estudar pra valer: leitura e produção de textos nas séries iniciais do Ensino Fundamental". Esse tipo de parceria se tornou frequiente a partir da década de 1990 com a elaboração de leis reguladoras das relações entre o governo e os vários organismos da sociedade civil por intermédio das leis das Organizações Sociais (OS) e do Voluntariado, em 1998 e da lei n ${ }^{\circ}$ 9790/99 que cria as Organizações da Sociedade Civil de interesse público (Oscips).

As reformas políticas implementadas na década de 1990 surgiram como uma resposta da burguesia à participação popular e à ação de grupos e classes sociais organizados na década anterior para defender seus interesses, procurando adequar o país aos ditames neoliberais fazendo surgir novas demandas sociais, novos sujeitos e novos valores difundidos plenamente pelos diversos aparelhos de Estado.

Historicamente a educação tem sido o objeto de política social mais discutido, sendo este o principal cabo eleitoral de muitos candidatos há muito tempo. De acordo com Vanilda Paiva (1991: pp. 181-188), ela é peça fundamental no processo de obtenção dos direitos políticos, integrando a pauta dos direitos sociais apoiada na contribuição para o desenvolvimento econômico-social e político, embora a educação das massas tenha se consolidado somente a partir do século XX.

É também um instrumento importante de conquista e manutenção de privilégios para os grupos dominantes, que não abrem mão dela como meio para se atingir cultura e conhecimentos que serão úteis para a formação do homem integral. Ao agirem assim, preservam o monopólio do saber por meio de escolas que estão a margem das políticas públicas de educação elaborada por eles.

Segundo a autora (1991: pp 182-183), faz parte do núcleo ideológico liberal a conexão entre educação e mobilidade social. Paiva afirma ainda que, embora pese a falta de clareza que no passado e ainda hoje reina em torno das funções sociais da escola e da educação em geral, seria difícil negar que elas contribuam para o bem-estar social, a geração de riqueza, a ampliação da cidadania, a ascensão individual e a estabilidade da ordem sócio-econômica.

Segundo Sonia Draibe (1997: p 3) a institucionalização das políticas sociais na América Latina pretendeu reorganizar, sob a perspectiva do mercado, o arcabouço institucional e regulatório do Estado e as formas concretas da intervenção das políticas públicas. Nesse sentido se pode afirmar que os programas sociais constituem um campo de especial interesse das reformas institucionais por dois motivos, por terem sido pouco reformados e por ter sido muito forte a inovação institucional experimentada pelas 
políticas, programas e mesmo sistemas nacionais de proteção social. Para Draibe a proteção social garante a manutenção do patamar mínimo de reprodução social, muito provavelmente em nível acima do que verificar-se-ia na ausência de tais inovações. Para ela, houve uma tendência a redistribuição principalmente em função do reforço e expansão dos programas universais de educação fundamental e de saúde, da tendência a redução da heterogeneidade das prestações securitárias e da maior integração entre os programas previdenciários, de saúde e de assistência social (1997: p. 05).

Já para Claus Offe (1995: p. 16) o próprio desenvolvimento do capitalismo gera problemas sociais tais como a necessidade de moradia para os trabalhadores concentrados em determinados lugares pela indústria, a necessidade de qualificação permanente da força de trabalho, desagregação familiar, ou seja, o capitalismo destrói formas anteriores de vida social (ou instituições sociais), gerando disfuncionalidades, que se expressam sob a forma de problemas sociais, aos quais o Estado deve assumir os encargos. Para o autor, a emergência de programas sociais não é resultado de escolhas, uma vez que as alternativas políticas são pequenas. São as condições econômicas e sociais que os determinam e não opções no campo do político. Para Offe os programas sociais são fundamentalmente mecanismos para corrigir ou compensar disfuncionalidades expressas no plano social, da operação do sistema capitalista.

Nos deparamos, dessa forma, com os problemas criados pela estrutura capitalista, que gera os desequilíbrios sociais para os quais nem sempre tem-se uma solução. O que temos verificado no Brasil, com relação às políticas públicas no campo social, é que essas nasceram com o processo de industrialização do país nas décadas de 1930/40 com o governo de Getúlio Vargas, porém, em relação a políticas educacionais no sentido de ampliação do acesso e permanência na escola, bem como as discussões acerca da necessidade de elaboração de propostas de mudanças no sistema educacional do país só se efetivaram nas décadas de 1980/90, junto com a abertura política ocorrida após os duros anos de autoritarismo do regime militar. Para que a educação assumisse lugar de destaque na pauta de políticas públicas foi necessária ampla mobilização popular em sua defesa a partir de diversos setores organizados da classe trabalhadora.

\section{A descentralização: do Estado a escola}

No Brasil da década de 1980 a noção de participação era diferente da que se instituiu a partir da década seguinte. Até então, sociedade civil organizada era sinônimo de participação popular e era um espaço ocupado pela classe trabalhadora que a entendia como um espaço de luta, de conquistas e disputas políticas e ideológicas, valorizadas pela busca permanente de transformação das estruturas políticas e sociais.

Com a implementação das políticas trazidas a tona pelo neoliberalismo, a sociedade civil se transformou em um lócus importante de consolidação da hegemonia burguesa à medida que assumiu o papel de disseminadora dos valores burgueses contribuindo para a descentralização das relações políticas e administrativas, inclusive e principalmente, no atendimento das necessidades sociais de parcelas significativas da classe trabalhadora. Assumindo esse papel, acabou por colaborar na ocultação de conflitos sociais e das contradições do próprio capital.

A contradição entre Estado e sociedade ficaria assim solucionada, pois o Estado, como educador, redefiniruia suas estratégias de obtenção do consentimento da população (NEVES, 2005, p. 91) por meio de estratégias que vão desde a reformulação do aparelho de Estado, ajustes econômicos, ajuste fiscal, controle do déficit público, flexibilização das 
relações de trabalho, reforma da previdência até a reforma educacional. A partir de então, impactos muito grandes podem ser observados em diversas áreas sociais principalmente já que o ajuste econômico significou a retirada de recursos aplicados no atendimento às necessidades básicas das camadas mais baixas da população, "precarizando as políticas sociais públicas e estimulando sua privatização" (NEVES, 2005, p. 92-93).

Ainda de acordo com Neves, a partir desse momento, as organizações não governamentais (ONGs) passaram a ter maior visibilidade ao mesmo tempo em que o Estado passou de produtor direto de bens e serviços a coordenador de iniciativas privadas. A privatização dos recursos e companhias estatais veio acompanhada por políticas de descentralização e desconcentração ampliando e modificando as formas de relacionamento com a sociedade.

Seguindo esta linha, a democratização da gestão escolar do ensino público foi inserida nesse processo mais amplo, pautando-se em três princípios fundamentais: elaboração e execução da proposta pedagógica, a participação dos profissionais da educação na elaboração do projeto pedagógico da escola e a participação das comunidades escolar e local em conselhos escolares, municipais ou equivalentes. De acordo com o artigo 15 da LDB, as unidades escolares passaram a ter asseguradas progressivos graus de autonomia pedagógica e administrativa e de gestão financeira (BRASIL, 1996).

Ao refletir sobre estas questões, alguns autores como Ilma Veiga (1998) afirmam ser essa autonomia, mesmo que delegada, uma importante aliada das escolas na definição de seus projetos educativos representando "um rompimento com o modelo administrativo autoritário centralizado, [reforçando] que a escola não tem mais possibilidade de ser dirigida de cima para baixo e na ótica do poder centralizador que dita as normas e exerce o controle técnico-burocrático". Salienta ainda que "a luta da escola é para a descentralização em busca de sua autonomia e qualidade". Carmem Moreira de Castro Neves (1998, p. 113) ao abordar a temática, aproxima seus conceitos aos de Veiga de que a autonomia é imprescindível para a escola, já que ela é "a possibilidade e a capacidade de a escola elaborar e implementar um projeto político-pedagógico que seja relevante à comunidade e à sociedade a que serve". Acredita que com a autonomia, além de poder organizar o seu projeto pedagógico, cada escola poderá organizar sua estrutura de forma completamente diferente de outras, pode ter flexibilidade de contratação e alocação de pessoal e uma base financeira que lhe dê condições de agir independentemente (NEVES, 1998, p. 114).

O princípio da autonomia traz a idéia de liberdade, democracia e participação e, estão presentes na LDBEN. Assim, a partir da aprovação desta lei, tanto os municípios quanto as escolas criaram seus órgãos colegiados deliberativos, os Conselhos Municipais de Educação e os Conselhos de Escola, respectivamente, com atribuições específicas ao seu funcionamento, cabendo aos Conselhos Municipais definir as políticas educacionais do município, desde as construções escolares, os salários e a formação de professores até a compra de materiais didáticos e livros, bem como integrar e avaliar o trabalho das escolas municipais, estaduais e privadas, além de discutir e aprovar o plano municipal de educação. Esses conselhos são formados por representantes do poder público e da sociedade civil organizada.

Os Conselhos de Escola tem atribuições consultivas, deliberativas e fiscais em questões definidas pela legislação estadual ou municipal e no Regimento Escolar. Essas questões geralmente envolvem aspectos pedagógicos, administrativos e financeiros. Em vários estados os Conselhos são eleitos no início do ano letivo, com uma composição que contempla certa proporcionalidade de participação dos docentes, dos especialistas em educação, dos funcionários, dos pais e alunos observando-se a paridade entre integrantes 
da escola, tendo como função básica democratizar as relações de poder. Nesses casos, o funcionamento do Conselho de Escola está relacionado ao processo de descentralização que deve estimular e abrir espaços para a participação de todos com autonomia.

Esta participação pode ser entendida como uma intervenção dos profissionais da educação e dos usuários na gestão da escola. Há aí implícitos dois sentidos de participação articulados entre si: a participação como meio de conquista da autonomia da escola, dos professores, dos alunos, constituindo-se como práticas formativas, como elemento pedagógico, metodológico e curricular e a participação como processo organizacional em que os profissionais e os usuários da escola compartilham, institucionalmente, certos processos de tomada de decisão.

Ocorre que da forma como estes conselhos estão organizados, não se pode esperar nada de transformador, dado que partem dos grupos dominantes em favor das camadas dominadas sem pressão por parte dos interessados (PARO: 2006). Por isso deve-se pensar inicialmente nas relações de poder na escola. Vitor Paro sugere que se comece questionando a função burocrática, hierárquica e autoritária exercida pelo diretor de escola, dado que esta lhe é conferida pelo Estado em que ele é o chefe de quem emanam todas as ordens na instituição escolar, que o leva inclusive a dividir os diversos setores dentro da escola, fazendo com que o diretor tendencialmente busque o interesse dos dominantes em oposição aos interesses dos dominados.

Para Vitor Paro, a forma como o diretor de escola se posiciona no seu cargo contribui para democratizar ou não as decisões na escola sendo que somente poderá haver essa democratização das instâncias inferiores de coordenação se ele perceber que ao se distribuir a autoridade entre os vários setores do ambiente escolar, ele não estará perdendo o poder, ao contrário, estará dividindo responsabilidade e, se isso acontecer, quem ganhará poder será a própria escola.

Nesse sentido, o Conselho de Escola só se tornará efetivamente importante,

Na medida em que conseguir a participação de todos os setores da escola - educadores, alunos, funcionários e pais - nas decisões sobre seus objetivos e seu funcionamento, [pois assim] haverá melhores condições para pressionar os escalões superiores a dotar a escola de autonomia e de recursos (PARO, 2006, p. 12).

Teoricamente o Conselho de escola como órgão colegiado e deliberativo, teria amplos poderes na articulação do ensino e como tal, poderia propor um tipo de educação mais direcionado ao atendimento das necessidades e interesses dos grupos representados, fazendo acontecer a educação pública, democrática e de qualidade que prega a legislação educacional brasileira, tão difundida pelos teóricos atuais.

Embora esteja em pauta tanto no meio acadêmico quanto nas instituições escolares de educação básica a discussão sobre a democratização da sociedade e da educação pública, apontando diversas contradições no entendimento da questão, do ponto de vista político social está ainda em curso a desresponsabilização do Estado diante de programas e propostas sociais quando este transfere para a sociedade civil parte da responsabilidade sobre os serviços públicos, ampliando o conceito de participação em que "haveria organismos privados voltados para [...] o interesse público ou bem comum" (MELO e FALLEIROS, 2005, p.181). Estes autores afirmam ainda que se trata de um processo de "publicização" que incidiria, sobretudo na implementação de políticas públicas sociais, ou seja, no trato direto com os diversos direitos sociais, como educação, saúde, esporte, lazer, artes, ciência e tecnologia em que o Estado não mais as executaria de forma exclusiva, mas, delegando sua execução às denominadas organizações públicas não-estatais. 
Complementam ainda que, essas organizações, se configurariam como formas de realização de parcerias entre o Estado e a Sociedade, sistematizando a participação de organismos deste tipo na implementação de políticas públicas,

a partir da noção de que tais mecanismos ampliariam a possibilidade de participação e controle por parte da sociedade civil, considerada de forma homogênea, foram apresentadas como formas modernas de superação dos modelos anteriores na relação Estado-sociedade (MELO e FALLEIROS, 2005, p. 184).

Nessa perspectiva, a responsabilidade da comunidade se ampliaria de tal forma que caberia a sociedade civil gerenciar setores importantes da vida social como a educação através de programas de solidariedade ou voluntariado representados em programas como os "Amigos da Escola" amplamente difundidos pelas organizações globo, símbolo maior da imprensa televisiva brasileira, bem como organizações não-governamentais, ONGs que, atendendo aos chamados governamentais, se posicionariam como planejadores, implementadores e executores de políticas públicas.

\section{As organizações não governamentais na condução da educação pública}

De modo geral, as organizações não-governamentais constituem parte de um fenômeno iniciado nos anos 1960, a partir da diversificação de associações de cidadãos na sociedade brasileira em defesa de direitos sociais e políticos. As ONGs configuram-se como organizações sem fins lucrativos, privadas e não-governamentais, e operam de forma individual, sendo até certo ponto competitivas entre si, na medida em que buscam a especialização em campos de atuação distintos. Quando surgiu, o termo nãogovernamental atestava a autonomia em relação aos governos, já que grande parte das ONGs surgiram como apoio técnico, jurídico e político a muitos movimentos sociais organizados nas décadas de 1970 e 1980.

De acordo com Nanci Valadares Carvalho no final dos anos 1970/80 constata-se

uma nova forma de governabilidade nas organizações das populações pobres e excluídas dos guetos de Nova York. Nos anos 90 essas organizações sofreram um boom, espalhando-se por todo o mundo. São centenas de milhares de ONGs que unem a tradição humana de altruísmo e generosidade de poucos indivíduos e organizações exemplares à força das massas contemporâneas em direção ao autogoverno (CARVALHO, 2008).

Durante a ditadura civil-militar surgiram várias ONGs no Brasil, mas foi durante as décadas de 1980/90 que houve um estrondoso crescimento no número dessas Organizações que passaram a atuar no país. Embora tenha sido ampliado o número de entidades, a partir dos anos 90 elas vêm experimentando transformações em seus paradigmas conceituais e estruturas organizacionais, deixando de atuar como entidades combativas e contestatórias ao lado dos explorados e assumindo posição mais colaborativa com o capital, sendo suas ações mais propositivas, especializadas e voltadas para o alcance de resultados.

Uma dessas instituições criadas para atuar no campo da educação pública é o CENPEC (Centro de Estudos e Pesquisas em Educação, Cultura e Ação Comunitária), uma organização da sociedade civil, sem fins lucrativos, criada em 1987, cuja finalidade 
explícita é "o desenvolvimento de ações voltadas à melhoria da qualidade da educação pública e à participação no aprimoramento da política social"5.

De acordo com as informações disponíveis no sítio institucional,

o CENPEC atua em programas e projetos que auxiliam as políticas públicas em educação. Através de parcerias com o poder público, em todos os seus níveis, e com instituições empresariais de forte relevância social, o CENPEC vem ajudando a melhorar a performance educacional do Brasil (http://www.cenpec.org.br).

Na gênese e desenvolvimento do projeto há a participação de inúmeros "parceiros" englobando desde entidades internacionais como a Unesco, a OIT, o Unicef e a WCF; como também fundações empresariais (Fundação Itaú Social, Fundação Telefônica, Fundação Volkswagen e Instituto Votorantin dentre outros); organizações nãogovernamentais brasileiras; empresas outras e órgãos governamentais incluindo o Ministério da Cultura e Ministério da Educação.

Os principais projetos do CENPEC estão ligados ao desenvolvimento da educação pública, por meio de apoio direto a ações no espaço escolar ou em ambiente social com a participação de organizações parceiras. Para se ter uma idéia da abrangência da atuação dessa instituição, os programas e projetos chegam na primeira década do século XXI a mais de 3 mil municípios, envolvendo estudantes e professores em quase todos os Estados brasileiros, atendidos pelos mais de trinta projetos em desenvolvimento6.

No estado de São Paulo treze prefeituras7 assinaram termos de parceria com o CENPEC no projeto intitulado "Estudar pra Valer" - Língua Portuguesa. De acordo com a proposta, o objetivo deste projeto era melhorar a qualidade de aprendizagem dos estudantes da rede escolar pública, em especial das capacidades de leitura e produção de texto, além de fortalecer as estruturas das redes municipais, "para que assumam com autonomia a condução da gestão educacional local", "instalar e fortalecer a cultura de formação contínua dos profissionais da educação e de acompanhamento das práticas escolares e da aprendizagem dos alunos" (http://www.cenpec.org.br).

Para atingir tais objetivos, a equipe do CENPEC atua em dois campos: a formação de professores e o acompanhamento das atividades realizadas na escola. Nesse sentido, "realiza encontros de formação com professores, coordenadores pedagógicos, diretores de escolas e técnicos de secretarias municipais de Educação, bem como acompanhamento das atividades na escola". Isso pressupõe autonomia da instituição até mesmo para a elaboração do currículo da escola, uma vez que esta define os conceitos educacionais que devem ser trabalhados incluindo a forma como vai se dar a avaliação. Em suas palavras

nesses encontros é realizado um estudo do material no que se refere à concepção de linguagem, a diferentes gêneros discursivos, ao trabalho com projetos de leitura e produção de textos, alfabetização, ortografia e análise lingüística, bem como, à concepção de avaliação. [Para que isso aconteça], os participantes são orientados para analisar as produções dos alunos e para elaborar o portfólio (http://www.cenpec.org.br).

Além disso, como a intervenção não se dá apenas no campo específico da atividade de sala de aula, abrange-se também os gestores das escolas e dos órgãos centrais:

os gestores recebem uma formação específica nos temas: gestão dos tempos e espaços para a aprendizagem; organização de uma sistemática de acompanhamento do ensino dos professores e da aprendizagem dos 
alunos articulada ao projeto político-pedagógico da escola [e] as equipes dos órgãos centrais são orientadas para acompanhar o trabalho das escolas e o resultado da aprendizagem dos alunos, propondo intervenções e replanejamentos para o ensino de todos (http://www.cenpec.org.br).

De acordo com dados do próprio CENPEC, em 2003, a proposta foi implantada em três escolas de São Carlos, alcançando 65 professores e 14 gestores, já com a parceria da Fundação Volkswagen. Segundo eles, cerca de metade dos alunos da rede municipal foi envolvida indiretamente. No ano seguinte, Limeira e Bebedouro entraram em contato com a concepção do projeto por meio de encontros realizados em São Carlos.

A descentralização administrativa indicada pela Constituição de 1988, complementada pela reforma do aparelho estatal na década seguinte levou a desconcentração de poderes, incluindo a administração da educação. A municipalização do ensino fez parte deste processo e assim, foi transferida para os governos locais a gestão das políticas públicas de educação no que tange a coordenação do processo educativo e a utilização dos recursos direcionados a melhoria da educação. Na aplicação desses recursos, recorrer a "parceiros" acaba se tornando uma constante, inclusive como forma de barganha política, mas também como uma forma de "terceirizar" o cuidado com a gestão, proposição e acompanhamento da educação municipal.

O CENPEC tem se colocado como o oásis que vai "fortalecer as estruturas das redes municipais, para que assumam com autonomia a condução da gestão educacional local. Instalar e fortalecer a cultura de formação contínua dos profissionais da educação e de acompanhamento das práticas escolares e da aprendizagem dos alunos" (http://www.cenpec.org.br). Entidades como estas acabam por assumir a responsabilidade do Estado na formulação de políticas educacionais com o argumento de melhorar a qualidade de aprendizagem dos estudantes da rede escolar pública, em especial das capacidades de leitura e produção de texto.

Se organizações não governamentais assumem a proposição de políticas públicas, surge a pergunta: Qual é o papel do Estado e dos indivíduos que estão fazendo a educação acontecer nas inúmeras escolas espalhadas pelo território? Tomando o conceito de Estado definido por Castanho (2003, p. 22) este se constitui apenas com a tarefa de definir, ampliar e consolidar sua base territorial, o país; de instituir e fixar no país a nação, sua base humana, conferindo-lhe unidade; de estabelecer, como cimentos dessa unidade, a língua, a cultura e a educação, tornando-as orgânicas em relação ao todo nacional; e de fornecer a legitimidade institucional da sociedade, considerada em seus aspectos políticos, econômicos e propriamente sociais, mediante o ordenamento jurídico. Ao Estado republicano cabe então criar a unidade em termos de valores e normas sociais, políticas, econômicas sendo a escola um importante instrumento na transmissão desses valores e, portanto, de conformação social. Evidente fica que ao se alterar a noção e função do Estado, as causas e as consequiências passam a ser intrinsecamente articuladas. Ao se negar a centralidade do Estado na formulação da política pública, transferindo para organismos privados esse papel, transfere-se também a função unificadora do Estado. Implícito está a noção de multiplicidade de órgãos administrativos do interesse público e com isso uma evidente fragmentação da sociedade. Ao se perder de vista a idéia de unidade, perde-se a noção de coletividade e de interesses comuns, levando a maior individualização e quebra da identidade da classe trabalhadora, ofuscando a visão dicotômica de explorados e exploradores.

Esta quebra de identidade da classe trabalhadora se dá também por meio do currículo escolar, já que a democratização e descentralização possibilitaram a cada cidade ter o seu plano de ensino direcionado à realidade local, proporcionando também a 
fragmentação dos objetivos da escola, pois levou a elaboração de projetos políticos e pedagógicos específicos para cada unidade educacional, mesmo se concentrando em realidades sociais semelhantes, ou seja, estando em bairros de histórico e necessidades idênticos, essas escolas tem projetos próprios e estão preocupadas em resolver seus próprios problemas e não se "solidarizam" com a comunidade a sua volta.

Perde-se, portanto, o padrão de homogeneidade do ensino, pois o que passa a prevalecer é a heterogeneidade tanto das instituições quanto dos conteúdos do ensino. A escola deixa de formar para um padrão nacional de ensino, e torna-se cada vez mais particularizada e isso levando a perda da noção de conjunto.

Segundo Castanho (2003, p. 22), a homogeneidade cultural é construída pelo Estado nacional como condição de sua existência original e para isso ele mobiliza a educação nacional buscando a homogeneidade lingüística e de valores culturais, difundidos pela comunidade nacional. Castanho afirma que a fase atual de globalização foi a que mais chocou com a cultura nacional, exatamente por que colidiu com o centro de sua irradiação, ou seja, o Estado Nacional e conclui que "o que se seguiu foi uma intensa desconstrução, atingindo a cultura nacional periférica em seus valores e até mesmo na sua expressão lingüística".

Aproveitando-se dessa possibilidade aberta, o CENPEC formula suas propostas de ensino e direciona as práticas pedagógicas das escolas por meio de seus projetos e especificamente o de leitura e escrita que atinge frontalmente a identidade nacional quando se pensa nos termos colocados por Castanho, pois,

Cada um dos projetos se desenvolve em torno de um tema ou de um ou mais gêneros discursivos. Assim, ao longo do ciclo, os alunos vão se familiarizando com os mais diferentes gêneros que circulam na sociedade e aprendem a fazer uso da língua em situações variadas.

A adesão por parte dos municípios ou escolas isoladamente ao projeto do CENPEC inclui a aquisição de material didático por parte das prefeituras conveniadas, liberação de professores para formação em serviço e contratação de professores substitutos para os dias em que os titulares da sala estão em treinamento e isso pressupõe utilização de verbas do Fundeb8. Além disso, as escolas aderem totalmente ao material didático produzido pela parceira, delegando a sua autonomia na escolha destes e, principalmente, na execução, já que o uso desse tipo de material padronizado de fora para dentro, acaba engessando o trabalho pedagógico da escola e do professor que torna-se mero aplicador da apostila, com prazos marcados para concluir as atividades e passar para a apostila seguinte e assim sucessivamente.

Para a administração pública, a proposta configura-se na necessária adequação da educação para o atual momento histórico, marcado por uma grande mudança econômica e social, conseqüência da nova ordem global (a globalização do capitalismo); do desenvolvimento de novas tecnologias e seu resultado para o mundo do trabalho. Além disso, o mercado necessita também de pessoas mais sensíveis aos problemas atuais, mais criativas e, sintonizadas com as novas exigências da sociedade e a escola se molda para preparar esse novo homem, como mostra o sitio do CENPEC na internet.

O projeto enfatiza o ensino da leitura e da produção de texto, habilidades básicas para que os alunos possam exercer sua condição de cidadãos e tenham acesso às demais áreas do conhecimento. Organiza-se em torno de projetos de leitura e escrita para que o ensino da língua se dê por meio de situações de uso efetivo. Em vez de exercícios mecânicos de 
memorização, os alunos aprendem a ler e a produzir textos em situações contextualizadas - são incentivados a trocar correspondência com outras escolas, organizar saraus de poesias, ler o jornal e elaborar entrevistas, dentre outras atividades (www.cenpec.org.br: 2008).

Em função das grandes transformações econômicas, tecnológicas, culturais e outras, adeptos desse entendimento afirmam que as ciências e o conhecimento daí decorrentes precisam passar por um processo de superação. A sociedade capitalista, agora, sob a égide da globalização do mundo, da economia, da cultura, dos valores, dos homens, bem como do grande desenvolvimento tecnológico, evidencia que o conhecimento especializado não serve mais como referencial de aprendizagem. O mundo é "complexo" e essa complexidade de conhecimentos deve ser abarcada pelos novos currículos escolares.

Na proposta implantada pelo CENPEC o trabalho educativo se dá por módulos e cada um dos projetos se desenvolve em torno de um tema ou de um ou mais gêneros discursivos. Assim, ao longo do ciclo, os alunos vão se familiarizando com os mais diferentes gêneros que circulam na sociedade e aprendem a fazer uso da língua em situações variadas, incluindo a manipulação de bulas e manuais de instalação de produtos. Com isso, a entidade acaba determinando os conteúdos a serem ensinados (ou a ausência de conteúdos), demonstrando estar afinada com o ideal neoliberal de cidadania, entretanto, a participação destas ONGs na formulação de políticas públicas não se dá no vazio, está fundamentado na própria LDB, no que diz respeito a organização da educação nacional, como dito anteriormente. No Título IV Da Organização da Educação Nacional detecta-se a indicação dos papéis da União, dos Estados e Municípios na elaboração de diretrizes que deverão nortear o currículo, evidenciando uma tendência neoliberal de descentralização político-administrativa, no entanto, resguardando ao Estado o poder de elaboração legal e de fiscalização, como defende Claus Offe:

Competências de área e de legislação, (financiamento e programação da pesquisa educacional), montagem de planos financeiros e esforços para a utilização econômica das facilidades disponíveis em prédios e pessoal, modernização da estrutura de decisão na escola e universidade e finalmente a decisão de limitar drasticamente os conflitos políticos que se manifestam no sistema educacional - estes temas, com os quais a política de educação tem se defrontado prioritariamente nos últimos anos, podem ser todos caracterizados como tentativas através das quais instâncias do Estado, se empenham em manter e elevar sua própria capacidade de intervenção político-educacional (1990: p. 38).

Ao delegar que outras instituições formulem os conteúdos a serem ensinados, esses municípios abrem mão do exposto no artigo 11 da LDBEN, que determina que cabe a eles organizar, manter e desenvolver os órgãos e instituições oficiais dos seus sistemas de ensino, integrando-os as políticas e planos educacionais da União e dos Estados. Desse modo, cabe aos estados e municípios elaborarem leis secundárias que deverão estar enquadradas nas diretrizes nacionais definidas. Essas diretrizes estão presentes no conjunto de publicações do MEC, os Parâmetros Curriculares Nacionais (PCNs) que é considerado um referencial de qualidade para a educação no Ensino Fundamental de todo o país. Este referencial tem a função de orientar e garantir a coerência dos investimentos neste nível de ensino. Também, por ter sido produzido à luz da produção pedagógica mais atual, cumpre com o papel de socializar discussões, pesquisas e recomendações aos professores e técnicos brasileiros, das mais remotas regiões. Para a CENPEC os PCNs se configuram numa proposta aberta e flexível, a ser concretizada nas decisões regionais e locais sobre 
currículos, sem, entretanto, ser um modelo curricular homogêneo e impositivo que fere as competências político-executivas de Estados e Municípios.

A diversidade sócio-cultural das diferentes regiões, bem como a "autonomia" de professores e equipes pedagógicas também são preservadas, de acordo com o documento, dentro daquilo que se pode abstrair de uma proposta curricular nacional, que cumpre com a função de homogeneizar em torno de um ideal de cidadania e de identidade nacional (no sentido de constituição de um conceito de Nação).

Para esses setores que aderiram ao neoliberalismo, a escola pública, enquanto escola do Estado, cumpre o seu papel como um instrumento de reprodução de uma visão essencialista de identidade nacional que foi decisivo nos dois últimos séculos (a História da Educação mostra como isso se deu no Brasil). A centralidade da Escola decorreu até agora, em grande medida, da sua contribuição para a socialização (ou mesmo fusão) de identidades dispersas, fragmentadas e plurais, que se esperava, pudessem ser reconstituídas em torno de um ideário político e cultural comum, genericamente designado de nação ou identidade nacional.

A intervenção do Estado teve, assim, um papel importante e decisivo na gênese e desenvolvimento da escola de massas (enquanto escola pública, obrigatória e laica) e esta não deixou de ter também reflexos importantes na própria consolidação do Estado. Pode mesmo dizer-se que a construção dos modernos Estados-nação não prescindiu da educação escolar na medida em que esta se assumiu como lugar privilegiado de transmissão (e legitimação) de um projeto societal integrador e homogeneizador, isto é, um projeto que pretendeu, mesmo coercitivamente, sobrepor-se (e substituir-se) as múltiplas subjetividades e identidades culturais, raciais, lingüísticas e religiosas originárias (AFONSO: 2001, p. 18).

Analisando por este ponto de vista estamos presenciando um enxugamento no papel do Estado, pois na formulação globalizante e neoliberal este foi destituído da centralidade de proponente das políticas públicas e passa a ser apenas o fiscalizador, assim como o projeto societário também acaba por fragmentar a sociedade.

Embora neste processo tenha sido instituído os PCNs que trazem explícitos, propostas de homogeneização, nas propostas educacionais atuais essa idéia é descartada em prol das formulações regionalistas, em que cada município articula a sua própria educação com uma curta vinculação com a educação nacional, evidenciando uma desarticulação da sociedade, pois cada um se preocupará com seu próprio sistema, com a gestão de seus próprios recursos e aquele que deveria ser o protagonista no processo de identidade nacional - o ensino comum - acaba se desmaterializando. Dá se então o reino dos micro-poderes, em que cada indivíduo ou grupo de indivíduos passa a se resguardar do poder do outro ou do estado em geral. E com isso vai sendo desmobilizado o projeto do Estado-Nação brasileiro tão difundido pelos liberais burgueses desde o século XIX, mesmo que pese ser a cultura transmitida pela escola uma imposição hegemônica da classe que está no poder.

Toda a proposta dos PCNs parte da necessidade de se instituir referenciais curriculares para o sistema educacional brasileiro, no entanto, defende o respeito às diversidades culturais, étnicas, religiosas e políticas. Isso, segundo o documento, é necessário, face à construção da cidadania numa sociedade que é múltipla, estratificada e complexa. A construção da cidadania tem como meta o ideal de igualdade entre os cidadãos e, para isso, é necessário o acesso à totalidade de bens públicos, entre eles, o 
conjunto dos conhecimentos socialmente importantes. Sabemos que a cidadania é historicamente um atributo político e cultural que pouco ou nada tem a ver com uma democracia substantiva ou com a democracia comprometida com a transformação social. No que diz respeito à reconfiguração ou ressignificação das cidadanias, há que ter em conta que a escola e as políticas educativas nacionais foram muitas vezes instrumentos para ajudar a nivelar ou a unificar os indivíduos enquanto sujeitos jurídicos, criando uma igualdade meramente formal que serviu (e ainda continua a servir) para ocultar e legitimar a permanência de outras desigualdades, como a de classe, por exemplo.

De acordo com a Introdução do PCN, a meta de qualidade em educação só será alcançada se forem previstas ações políticas e executivas em conjunto com os PCNs. Essas políticas sociais e educacionais são instrumentos de controle social, formas de legitimação da ação do Estado e interesses das classes dominantes. Nesse aspecto, a política educacional é, entre todas as outras políticas setoriais, talvez o exemplo mais patente de como o Estado procura produzir uma aparência de igualdade de condições e com isso de uma neutralidade em relação às classes no que concerne às suas próprias funções, quando na verdade, o status e as oportunidades de vida dos indivíduos estão ligados ao movimento de uma economia regulada pelo lucro. A propagação desta visão incomumente ligada a imagem de uma sociedade na qual cada opção está aberta a cada um praticamente a todo momento é determinada e adequada ao obscurecimento do fato de que nem a política educacional é livre para realizar esta visão, nem o destino social dos indivíduos é determinado por aquilo que eles aprenderam ou acreditam fazer na escola (OFFE: 1990, p. 41).

Assim, assumir a cidadania como eixo da educação escolar, supõe o comprometimento com a adoção de valores e de conhecimentos que contribuam para o desenvolvimento das capacidades necessárias para a participação social. O que convém repensar são as maneiras como se constroem esses conceitos de cidadania e até que ponto ela é uma realidade social conquistada, via organização civil ou uma cidadania tutelada, criada pelo Estado, para nos dar a impressão de liberdade política de expressão e manifestação de idéias, sem que, no entanto, se efetive com direitos sociais (educação, seguridade social, saúde, etc.) para a grande massa de excluídos do país.

Sendo a democracia e a participação tuteladas e delegadas pelo Estado, o âmbito de representatividade dos e nos grupos fica deficitária. A legislação tanto federal, quanto estadual e municipal determinam quais são as possibilidades de atuação de cada membro dos conselhos e geralmente esses existem apenas para ratificar decisões tomadas fora do espaço escolar ou a aplicar a legislação que nem sempre estão focadas na realidade local como tanto se fala.

Discutir e elaborar planos que representem os interesses dos grupos acaba sendo utópico, pois esbarra na estrutura jurídica que dá respaldo ao autoritarismo do Estado. As pessoas acabam acreditando numa pseudo-participação com limites são bastante tênues. E acreditando nessa forma de participação, acabam acreditando que a tutela do Estado é necessária e acabam sendo conduzidas ao conformismo e ainda assumem a responsabilidade pelo colapso da educação pública já que participam de tomadas de decisões, mesmo que sejam decisões secundárias. O cidadão não participa de instancias de decisões sobre a política pública de educação, sobre o conteúdo a ser ministrado, sobre a prática pedagógica da escola e nem sobre os recursos a serem utilizados, pois esses já são pré-determinados e o que os conselhos fazem é ratificar e assinar a prestação de contas.

Assim, ficam distante da construção de uma sociedade democrática em que a escola seja regida pelos mesmos princípios e que atenda aos seus interesses, ou seja, uma escola 
pública, única, que possibilite o acesso aos conhecimentos socialmente acumulados e que conduza o cidadão ao desenvolvimento integral, físico, intelectual e tecnológico.

\section{Referências:}

AFONSO, Almerindo Janela. Reforma do Estado e Políticas Educacionais: entre a crise do EstadoNação e a Emergência da Reforma Supranacional. In Educação \& Sociedade, ano XXII, $n^{\circ} 75$, Agosto/2001.

ANDERSON, Perry. Balanço do Neoliberalismo. In SADER, Emir, GENTILLE, Pablo. Pósneoliberalismo: as políticas sociais e o Estado Democrático. Rio de Janeiro. Paz e Terra. $5^{\text {a }}$ edição. 2000 .

ARRETCHE, Marta T. S. Emergência e Desenvolvimento do Welfare State: Teorias Explicativas. BIF: Rio de Janeiro, $n^{\circ} 39,1^{\circ}$ semestre 1995. pp. 3-40

BRASIL. Leis de Diretrizes e Bases da Educação Nacional. Lei 9394/96. In: Brasil, Ministério da Educação, Secretaria de Educação Média e Tecnológica.

BRASIL. Parâmetros Curriculares Nacionais. Vol. 1. Introdução. Brasil, Ministério da Educação, Secretaria de Educação Fundamental. 3. ed. Brasília: A Secretaria, 2001.

CASTANHO, Sérgio. Globalização, redefinição do Estado nacional e seus impactos. Lombardi. José Claudinei. Globalização, pós-modernidade e educação: história, filosofia e temas transversais. Campinas, SP: Autores Associados; HISTEDBR, Caçador, SC: UnC, 2003.

DRAIBE, Sonia Miriam. Uma Nova Institucionalidade das Políticas Sociais? Reflexões a propósito da experiência latino-americana. In DRAIBE, Sonia Miriam. As Políticas Sociais e o neoliberalismo. Reflexões suscitadas pelas experiências latino-americanas. In Revista USP. Sd/pp. $86-101$

http://www.mp.gov.br/arquivos_down/seges/publicacoes/reforma/seminario/NEDER.PDF

http://www.planetanews.com/produto/L/112168/autogestao--o-nascimento-das-ongs-nancivaladares-carvalho.html acessado em 12/08/2008.

KING. Desmond S. O Estado e as estruturas Sociais de bem-estar em democracias industriais avançadas. In Novos Estudos. CEBRAP. N²2, outubro de 1998. pp. 53-76.

MELO, Marcelo Paula de. FALLEIROS, Ialê. Reforma da aparelhagem estatal: novas estratégias de legitimação social. NEVES, Lucia Maria Wanderley (org). A nova pedagogia da hegemonia: estratégias do capital para educar o consenso. São Paulo: Xamã, 2005. pp. 174-192.

NEVES, Carmem Moreira de Castro. Autonomia da Escola Pública: um enfoque operacional. VEIGA, Ilma Passos A. (org). Projeto Político Pedagógico da Escola: uma construção possível. $7^{\text {a }}$ ed. Campinas, SP: Papirus, 1998. pp. 95-129.

NEVES, Lúcia Maria Wanderley. A sociedade civil como espaço estratégico de difusão da nova pedagogia da hegemonia. NEVES, Lucia Maria Wanderley (org). A nova pedagogia da hegemonia: estratégias do capital para educar o consenso. São Paulo: Xamã, 2005. pp. 174-192.

OFFE Claus. Sistema Educacional, sistema ocupacional e política da educação. Contribuição a determinação das funções sociais do sistema educacional. In Educação \& Sociedade, n 35, abril/90. pp 9 a 59. 
OFFE Claus. Teoria do Estado e Política Social. In Problemas estruturais do Estado Capitalista. Rio de Janeiro. Tempo Brasileiro. 1994. pp. 10- 53

PAIVA, Vanilda. Educação e Bem-estar Social. In Educação e Sociedade, n 39, agosto de 1991. pp. 161-200.

PARO, Vitor Henrique. Gestão Democrática da Escola Pública. $3^{a}$ ed. São Paulo: Ática, 2006.

PERONI, Vera. Política Educacional e papel do Estado no Brasil nos anos 1990. São Paulo: Xamã, 2003.

SAVIANI, Dermeval. Breves considerações sobre fontes para História da Educação. In Estudo Pensamento e Criação. Campinas, Gráfica FE, 2005.

TELLES, Vera da Silva. A "nova questão social” brasileira. In PRAGA. N 06. setembro 1998. HUCITEC Editora. Pp. 107-116.

TELLES, Vera da Silva. Sociedade Civil e Construção de Espaços Públicos. In A Trajetória dos Movimento Sociais. S/d.

VEIGA, Ilma Passos A. (org). Projeto Político Pedagógico da Escola: uma construção possível. $7^{\mathrm{a}}$ ed. Campinas, SP: Papirus, 1995.

1 Professor do Departamento de Educação (DEd) e do PPGE UFSCar - São Carlos/SP. Email: lbezerra@ufscar.br

2 Professora do Departamento de Educação (DEd) e do PPGE UFSCar - São Carlos/SP. Email: cbezerra@ufscar.br

${ }^{3}$ Professor do Departamento de Educação (DEd) e do PPGE UFSCar - São Carlos/SP. Email: mnelito@yahoo.com.br

${ }^{4}$ O governo de Fernando Henrique Cardoso iniciou a Reforma do Estado calcada na redefinição do papel do Estado, que deixa de ser o responsável direto pelo desenvolvimento econômico e social e pela via da produção de bens e serviços para fortalecer a função de promotor e regulador. Objetivava reforçar a capacidade de governabilidade através da transição programada de um tipo de administração pública, burocrática para uma administração pública gerencial, flexível e eficiente (PERONI, 2003, 58-9).

${ }^{5}$ Estes dados e todos os outros a seguir sobre o CENPEC, são retirados do sítio institucional da organização disponível em http://www.cenpec.org.br.

${ }^{6}$ A lista completa desses projetos está disponível no sítio institucional.

${ }^{7}$ Bebedouro, Americana, Guará, Hortolândia, Itanhaém, Limeira, Peruíbe, São Bernardo do Campo, São Carlos, Tatuí, Itu, Pirapora do Bom Jesus e Poá.

${ }^{8}$ Fundo Nacional de desenvolvimento da Educação Básica.

Artigo recebido em:23/09/10

Aprovado em: 30/10/10 